\title{
Emergence of Multi-Drug Resistant Clinical Strains of Staphylococcus aureus
}

\author{
Saha B and Bal M \\ Laboratory of Microbiology, Department of Physiology, University College of Science and Technology, \\ University of Calcutta, 92, A. P. C. Road, Kolkata-700009, India
}

[Received: December 22, Accepted: December 30, 2013]

\begin{abstract}
Indiscriminate and wide spread use of antibiotics has lead to the development of multi-drug-resistant strains of pathogenic Staphylococcus aureus. Information regarding increase (in percentage) of existing resistance as well as emergence of new resistance to different antibiotics used for staphylococcal infections are insufficient. This study explores a comparative analysis of growing resistance to different antibiotics mainly ampicillin, methicillin, erythromycin, gentamicin, clindamycin and vancomycin against $S$. aureus isolated from Kolkata hospitals during two phases. During first phase (126) and second phase (67) non-repeat clinical strains of $S$. aureus obtained from different hospitals of Kolkata were identified by standard biochemical methods. However, PCR amplification of nuc gene and rDNA was also performed for identification of $S$. aureus. Antibiotic susceptibility pattern was determined by Disc Agar Diffusion tests and $m e c A$ was identified by PCR. Comparative analysis of antibiotic resistance pattern of the strains isolated during two phases showed significant difference ( $\mathrm{p}=0.05$ ) with $75 \%$ increase of resistance to erythromycin followed by $30 \%$ increase to ampicillin, chloramphenicol and streptomycin with the appearance of vancomycin resistance. Gentamicin and methicillin resistance have increased by $22 \%$ and $7 \%$ respectively. On the other hand, $m e c A$ was obtained by PCR from vancomycin resistant $S$. aureus strain, which was also resistant to methicillin, erythromycin and clindamycin. This study reveals tremendous increase of resistance to erythromycin and a remarkable increase to other antibiotics with emergence of multidrug-resistant clinical strains of $S$. aureus. This trend in increasing resistance to the commonly used antibiotics against $S$. aureus cannot be controlled until and unless antibiotics are used more prudently.
\end{abstract}

Key words: Erythromycin resistance, $m e c A$, MRSA, multi-drug resistance, Staphylococcus aureus

\section{INTRODUCTION}

Staphylococcus aureus, a major cause of potentially life-threatening infections acquired in health care and community settings. S. aureus causes a wide variety of suppurative diseases in man, including superficial and deep abscesses, and wound infections ${ }^{[1]}$. In addition, Staphylococcus can cause skin, heart valve, blood and bone infection, which can lead to septic shock and death. More than $90 \%$ of S. aureus elaborate penicillinases or beta-lactamases and $20-30 \%$ of S. aureus are methicillin resistant (MRSA) ${ }^{[2,3]}$. The prevalence of MRSA in India is also on the rise and there are reports of detecting MRSA in community acquired infections though the prevalence is much lesser ${ }^{[4,5]}$. MRSA strains also demonstrate a high degree of resistance to other antibiotics especially beta-lactams, and non- $\beta$ lactam antibiotics, such as macrolides, lincosamides, quinolones, tetracyclines and aminoglycosides. In particular, the majority of MRSA strains are not susceptible to macrolides and aminoglycosides, because the genes $\operatorname{ermA}$ and aadD encoding resistance to these drugs are usually conserved within mec DNA, and located upstream and downstream, respectively, of the mecA gene ${ }^{[6]}$. Erythromycin resistance in Staphylococcus aureus is part of the macrolidelincosamide-streptogramin B resistance phenotype. This phenotype was first described by
Chabbert shortly after the introduction of erythromycin in clinical practice ${ }^{[7]}$.

This is an endeavor to get a clear picture of the current trends in antibiotic resistance among the clinical strains of $S$. aureus isolated from Kolkata hospitals and to make a comparative analysis of antibiotic resistance pattern among the strains isolated in two phases.

\section{MATERIALS AND METHODS}

\section{Bacterial strains:}

First phase collection: Earlier (a few years back), one hundred twenty six (126) strains of $S$. aureus were collected from the Calcutta Medical College $\&$ Hospital (CMC). Second phase collection: Sixty seven (67) non-repeat clinical isolates of $S$. aureus have been collected recently from various Kolkata hospitals, which are the Calcutta Medical College \& Hospital (CMC), School of Tropical Medicine (STM), Institute of Child Health (ICH), R. G. Kar Medical College \& Hospital (RGK), Nilratan Sirkar Medical College and Hospital (NRS) and Seth Sukhlal Karnani Medical College \& Hospital (SSKM). All these strains were collected to study the antibiotic resistance profile of $S$. aureus. For collection of strains, no specific criterion was adapted. All cultures were grown in nutrient agar (NA) medium and purified by single colony isolation technique in NA containing $10 \%$ sodium chloride. 


\section{Confirmation of species identification:}

Identification of the clinical isolates of $S$. aureus was performed by traditional biochemical tests, including catalase, coagulase, mannitol fermentation tests, and Gram-staining ${ }^{[8,9]}$. PCR amplification of $n u c$ gene ${ }^{[10]}$ was performed. PCR amplification of 16S rDNA [11] was also performed.

\section{Antibiotic susceptibility testing:}

Antibiotic resistance profile was determined by Disc Agar Diffusion (DAD) technique ${ }^{[12,13]}$, using eighteen antibiotic discs. Among these antibiotics, some discs were prepared in this laboratory and a few were obtained commercially from Himedia (Mumbai, India). The name of antimicrobials, its manufacturer and the concentration in $\mu \mathrm{g}$ of antimicrobials per disc, were as follows: amoxycillin (AMX, Rexcel, India; 30 $\mu$ g), ampicillin (AMP, Biochem Pharmaceutical Industries, India; 10 $\mu$ g), cefepime (FEP, Unichem Laboratories, India; 30 $\mu$ g), cefotaxime (CTX, Alkem Laboratories Ltd, India; 30 $\mu \mathrm{g}$ ), cefuroxime (CXM, Glaxo Smith Kline, India; 30 $\mu \mathrm{g}$ ), cephalexin (LEX, Ranbaxy, India; 30 $\mu$ g), chloramphenicol (CHL, Sigma, USA; 30 $\mathrm{g}$ ), ciprofloxacin (CIP, Pharma(Ran), India; 5 $\mu \mathrm{g}$ ), clindamycin (CLI, Indipharma, India; $2 \mu \mathrm{g}$ ), erythromycin (ERY, Alembic, India; 15 $\mu \mathrm{g}$ ), gentamicin (GEN, Nicholas, India; 10 $\mu \mathrm{g}$ ), methicillin (MET, Himedia, India; $5 \mu \mathrm{g}$ ), oxacillin (OXA, Himedia, India; $1 \mu \mathrm{g}$ ), rifampicin (RIF, Lupin, India; $5 \mu \mathrm{g}$ ), roxithromycin (ROX, Alembic, India; $15 \mu \mathrm{g}$ ), streptomycin (STR,

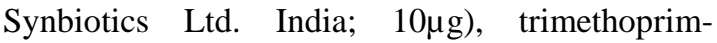
sulfamethoxazole (1:5) (SXT, Piramal Health Care, India; $5 \mu \mathrm{g}$ ) and vancomycin (VAN, Lilly

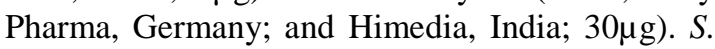
aureus ATCC25923, an all sensitive reference strain was used as a quality control strain for DAD test.

The test bacteria, taken from an over-night culture (inoculated with a single colony) were freshly grown in MHB for 4 hours at $37^{0} \mathrm{C}$. A bacterial lawn was prepared on MHA plate by spreading with this 4hours culture. Filter paper discs of 6 $\mathrm{mm}$ size soaked in antibiotic solutions (conc. of the antibiotics per disc are given above) were put in the inoculated MHA plate and incubated overnight at $37^{\circ} \mathrm{C}$. The zone of bacterial growth inhibition surrounding the antibiotic disc was measured and compared with a standard for each drug. This result gives a profile of drug susceptibility vis-à-vis antibiotic resistance.

\section{Determination of Minimum Inhibitory Concentration: \\ Minimum Inhibitory Concentration (MIC) of vancomycin was determined by broth microdilution method using Mueller-Hinton broth}

(MHB, dehydrated, Himedia, Mumbai) as recommended by National Committee for Clinical Laboratory Standards, renamed as CLSI ${ }^{[14]}$. The cut-off MIC for vancomycin resistance used by us was $32 \mu \mathrm{g} / \mathrm{ml}$. Most isolates of S. aureus are susceptible to vancomycin. The concentration of vancomycin required to inhibit these strains (called the minimal inhibitory concentration or MIC) is typically between 0.5 and 2 micrograms $/ \mathrm{mL}(\mu \mathrm{g} / \mathrm{mL})$. In contrast, S. aureus isolates for which vancomycin MICs are 4-8 $\mu \mathrm{g} / \mathrm{mL}$ are classified as vancomycin-intermediate, and isolates for which vancomycin MICs are $\geq 16$ $\mu \mathrm{g} / \mathrm{mL}$ are classified as vancomycin-resistant. The revised definitions for classifying isolates of $S$. aureus are based on the interpretive criteria published in January 2006 by the Clinical and Laboratory Standards Institute (CLSI, formerly NCCLS) ${ }^{[14]}$.

\section{Preparation of genomic DNA:}

Genomic DNA was prepared following the standard protocols.

\section{Polymerase Chain Reaction (PCR):}

The PCR amplification was performed with the thermal cycler ABI 9700 (ABI, Foster city, USA), in a volume of $50 \mu \mathrm{l}$. For amplification of nuc gene and mecA, the following components were used: $1.5 \mathrm{mM} \mathrm{MgCl}_{2}, 200 \mu \mathrm{M}$ each of dATP, dTTP, dGTP, dCTP, $2 \mu \mathrm{M}$ of each primer, $0.1 \mu \mathrm{g}$ of template DNA, and $1.25 \mathrm{U}$ of Taq polymerase (Invitrogen, Brazil).

\section{i) PCR amplification of nuc gene :}

Partial nис gene was amplified using nис Forward (5'-GCGATTGATGGTGATACGGTT-3') and nис Reverse

(5'AGCCAAGCCTTGACGAACTAAAGC-3') PCR primers, which were selected on the basis of the published nucleotide sequence of the $966 \mathrm{bp}$ пис gene derived from $S$. aureus Foggi strain ${ }^{[10]}$. The cycling parameters consisted of 30 cycles of denaturation at $94^{\circ} \mathrm{C}$ for $30 \mathrm{sec}$, primer annealing at $50^{\circ} \mathrm{C}$ for $1 \mathrm{~min}$ and extension at $72^{\circ} \mathrm{C}$ for $1 \mathrm{~min}$ $30 \mathrm{sec}$.

\section{ii) PCR amplification of $m e c A$ :}

For amplification of mecA, oligonucleotide primers mecA-Forward (5'TGGCTATCGTGTCACAATCG-3') and mecAReverse (5'-CTGGAACTTGTTGAGCAGAG-3'), were used [15]. The reaction condition was 30 cycles of denaturation at $94^{\circ} \mathrm{C}$ for $40 \mathrm{sec}$, primer annealing at $52^{\circ} \mathrm{C}$ for $45 \mathrm{sec}$ and extension at $72^{\circ} \mathrm{C}$ for $30 \mathrm{sec}$.

\section{Statistical Analysis:}

The statistical analysis of antibiotic resistance between the two periods was performed by following the conventional two- tail ' $t$ '' - test. 


\section{RESULTS AND DISCUSSION}

126 pathogenic strains of Staphylococcus aureus were obtained from various patients from the Calcutta Medical College and Hospital in $1^{\text {st }}$ phase and 67 strains from the Calcutta Medical College and Hospital as well as from other Medical Colleges and Hospitals of Kolkata in $2^{\text {nd }}$ phase. The clinical records of the strains of $S$. aureus collected from the Calcutta Medical College and Hospital in $1^{\text {st }}$ phase showed that strains collected from male patients were $62.7 \%$ and from female patients were $37.3 \%$. Strains collected from indoor patients were $76 \%$ and from outdoor patients $24 \%$. The sources were pus, blood, sputum, urine, throat swab, wound swab, vaginal swab, cerebrospinal fluid (CSF) etc. Maximum numbers of $S$. aureus strains were found from the pus.

The strains were gram-positive, catalase and coagulase positive, and mannitol fermenting.

Antibiotic resistance profile (of the strains collected in $1^{\text {st }}$ phase) obtained by Disc Agar Diffusion (DAD) tests showed that maximum strains of $S$. aureus were resistant to beta-lactam group of antibiotics, i.e. $86 \%$ strains of $S$. aureus were penicillin resistant followed by $66 \%$ to ampicillin. MRSA were found to be $23 \%$. Next peak of resistance was observed of tetracycline (54\%), followed by chloramphenicol (41\%). Aminoglycosides resistances were found to be as follows streptomycin, 38\%; kanamycin, 34\%; gentamicin, 3\%. Macrolide (erythromycin) resistance was $17 \%$.

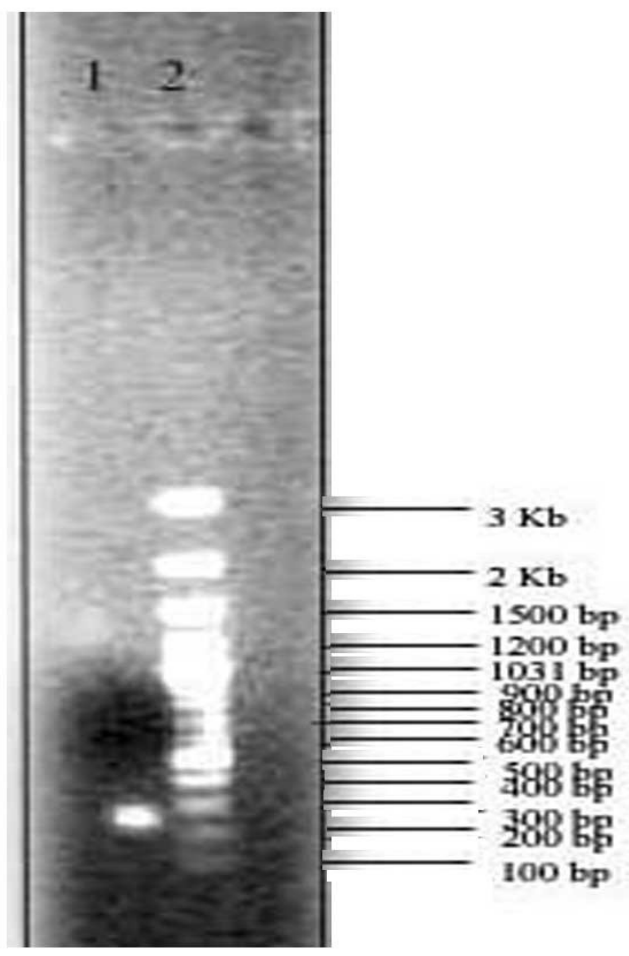

Figure 1: Agarose gel electrophoresis of PCR amplified nuc gene of a clinical strain of $S$. aureus. Lane: 1, amplified product of $n u c$ gene $(270 \mathrm{bp})$. Lane: 2, $100 \mathrm{bp}$ DNA ladder as molecular size marker.
Sixty seven clinical isolates of $S$. aureus collected from various Kolkata hospitals in $2^{\text {nd }}$ phase were also identified by gram-staining and other traditional biochemical tests. They were also gram-positive, catalase and coagulase positive, and grown on mannitol-salt-agar (MSA) medium. From these strains ( $2^{\text {nd }}$ phase) one strain of $S$. aureus, which was found to be vancomycin resistant, was identified by PCR amplification of nuc gene encoding thermonuclease, which is highly specific for S. aureus [Figure 1]. The PCR amplification of rDNA for this strain was also performed [data not shown].

Antibiotic resistance profile of the strains (obtained in $2^{\text {nd }}$ phase) found by Disc Agar Diffusion (DAD) tests showed maximum resistance to ampicillin (95\%), followed by erythromycin $(92 \%)$, roxithromycin $(86 \%)$, chloramphenicol (71\%), streptomycin (67\%), gentamicin $(25 \%)$, methicillin, oxacillin $(30 \%)$, Strains were also resistant to cotrimoxazole $(80 \%)$, amoxycillin (78\%), ciprofloxacin (77\%), and clindamycin $(57 \%)$. Cephalosporin group of antibiotics e.g., cefepime $\left(4^{\text {th }}\right.$ generation cephalosporin), cefotaxime $\left(3^{\text {rd }}\right.$ generation $)$, cefuroxime ( $2^{\text {nd }}$ generation), and cephalexin (1st generation), resistances were also found to a great extent. Resistances to vancomycin and rifampicin were also observed. The majority of methicillin resistant $S$. aureus (MRSA) strains were also resistant to erythromycin, streptomycin, kanamycin and clindamycin. The methicillin resistant strains MC48 and STM2 were also found to be erythromycin and clindamycin resistant. STM2 was also resistant to the glycopeptide antibiotic vancomycin. $49 \%$ of clinical strains of $S$. aureus were found to be vancomycin resistant apparently by disc agar diffusion test. The size of zone of inhibition of bacterial growth for vancomycin sensitive strain is $15 \mathrm{~mm}$ or more (for $S$. aureus ATCC25923 it is $17-21 \mathrm{~mm}$ ); $14 \mathrm{~mm}$ or less for VRSA. The sizes of zone of inhibition of 32 strains among 67 strains of $S$. aureus were found to be $12-14 \mathrm{~mm}$. But for $S$. aureus STM2 it was only $6 \mathrm{~mm}$. So for further confirmation, MIC determination was performed. The MIC value of the strain STM2 was found to be $64 \mu \mathrm{g} / \mathrm{ml}$ but, for the remaining $32(49 \%)$ strain, it was only $1-2$ $\mu \mathrm{g} / \mathrm{ml}$.

Finally a comparative analysis of antibiotic resistance pattern of the clinical isolates of $S$. aureus obtained in $1^{\text {st }}$ phase and $2^{\text {nd }}$ phase was done [Figure 2], which showed 30\% increase of resistance to ampicillin, chloramphenicol, and streptomycin. Maximum increase of resistance (75\%) was observed to erythromycin. Gentamicin resistance has increased by $22 \%$. Seven percent increase of resistance to methicillin was also noticed. The statistical analysis of antibiotic resistance between the two phases was performed 
by following the conventional two-tail' $t$ ' - test and it was found that the difference of antibiotic resistance between these two periods is significant at $\mathrm{P}$ level of 0.05 .

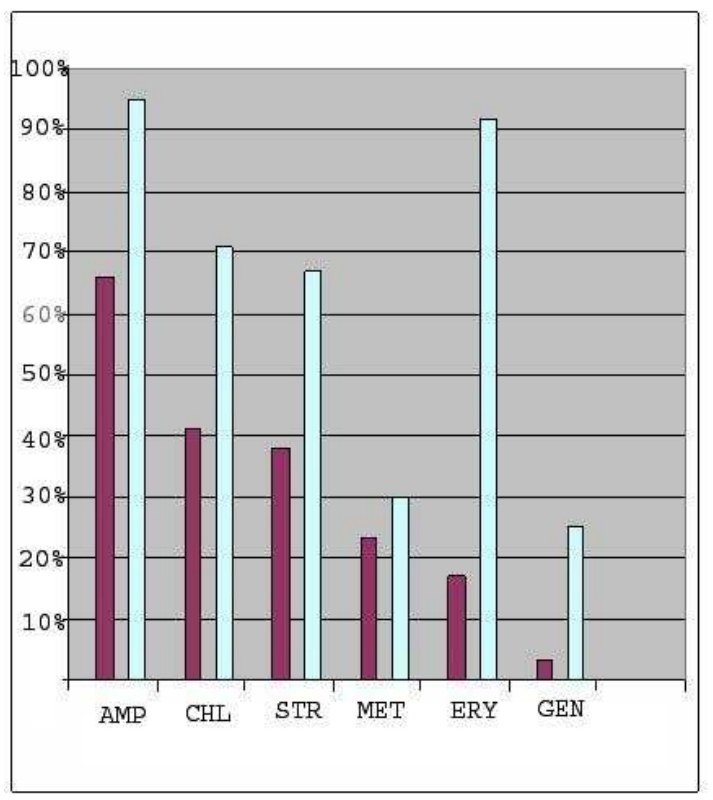

Figure 2: A comparison of antibiotic resistance pattern of clinical strains of $S$. aureus obtained during $1^{\text {st }}$ phase (Red Bar) and $2^{\text {nd }}$ phase (Blue Bar). Antibiotics are, AMP: ampicillin; CHL: chloramphenicol; STR: streptomycin; MET: methicillin; ERY: erythromycin; GEN: gentamicin.

A dramatic increase in the number of health care and community associated infections due to macrolide resistant $S$. aureus, clindamycin resistant $S$. aureus and MRSA highlight the success of this species $S$. aureus as a pathogen and its ability to adapt under pressure from antimicrobial agents. More than $30 \%$ of $S$. aureus have been reported to be MRSA. Vancomycin (the drug of last resort for enterococcal and staphylococcal infections) resistant S. aureus (VRSA) has also been reported from India ${ }^{[16]}$. Erythromycin resistance and clindamycin (used for soft tissue and bone infection) resistance are increasing very sharply. Apart from this it has been reported that methicillin resistant $S$. aureus is also resistant to all other beta-lactam and non-betalactam antibiotics ${ }^{[6]}$. But there is no report of the pattern / trends in increasing resistance to different antibiotics against clinical strains of $S$. aureus in the last few decades and the emergence of new antibiotic resistance from Kolkata as well as India, which motivated us to make a thorough investigation about the current trends in antibiotic resistance among the clinical strains of $S$. aureus from Kolkata (India).

Strains collected from indoor patients were $76 \%$ and from outdoor patients were $24 \%$. Hence the maximum strains of $S$. aureus collected from the Calcutta Medical College and Hospital were indoor strains. The resistance pattern of clinical isolates of $S$. aureus of $1^{\text {st }}$ phase showed that penicillin resistance had reached very close to $90 \%$ as reported by other authors also ${ }^{[2,3]}$. Ampicillin resistance was also found to be very high i.e. $66 \%$. But at that period erythromycin and other aminoglycosides resistance was very low.

But the antibiotic resistance profile of the strains of $2^{\text {nd }}$ phase showed maximum resistance to ampicillin (95\%), followed by erythromycin $(92 \%)$. The $\beta$-lactam group of antibiotics became almost useless as because ampicillin resistance has reached to nearly $100 \%$, followed by amoxycillin, and cephalosporins. Resistance to macrolides has increased significantly very high in the $2^{\text {nd }}$ phase i.e. erythromycin, $92 \%$ and roxithromycin, $86 \%$; most probably due to indiscriminate and wide use of erythromycin and roxithromycin for any skin infection as well as other infectious diseases. Many times we get infections due to multiple micro-organisms; that is why clinicians use broadspectrum antibiotics. As a result the co-infecting other pathogens and non-pathogens become resistant to all commonly used antibiotics. Here, in this study, we can see that ciprofloxacin, chloramphenicol, cotrimoxazole resistances have reached to $77 \%, 71 \%$, and $80 \%$ respectively which are not generally used for $S$. aureus infection. So the multi-drug-resistance phenomena are increasing more and becoming more complicated due to acquiring multi-drug-resistance genes from the gene-pool existing in nature due to indiscriminate and wide use of antibiotics. The MRSA strains utilize PBP2A (mecA) for the formation of cell-wall. But the other penicillin resistant $S$. aureus strains form cell-wall using other PBPs. This result also showed high ampicillin resistance $(95 \%)$ and amoxicillin resistance $(78 \%)$. This large difference of sensitivity is due to the variation of minimal inhibitory concentration (MIC) of antibiotics. The MIC of an antibiotic is not same for all strains; that is why, the sensitivity varies from strain to strain. It is one of the reasons of strain difference.

We have obtained PCR amplified product of mecA gene from VRSA STM2 (data not shown), which was also methicillin resistant, erythromycin resistant and clindamycin resistant. So the mecA gene in VRSA STM2 may also contain erythromycin resistance gene $\operatorname{ermA}$, which strongly supports the statement of Chambers, the majority of MRSA strains are not susceptible to macrolides and aminoglycosides, because the genes ermA and aadD encoding resistance to these drugs are usually conserved within mec DNA ${ }^{[6]}$. Among the strains collected in $1^{\text {st }}$ phase and $2^{\text {nd }}$ phase we have obtained many multi-drug-resistant (MDR) S. aureus strains; because they are methicillin resistant, erythromycin resistant, clindamycin resistant as well as aminoglycosides resistant. Those are MC3711, MC139, MC154, MC188, MC327, MC387, MC703, MC790, 
MC905, MC123, MC2887, MC207, MC48, MC50, STM2, NRSp146, NRSpL, NRSp157. We have obtained plasmid DNAs of different sizes from MC123, MC154, MC790 and MC2887 also, which may harbor mecA and erm genes in these organisms having Chabbert phenotype ${ }^{[7]}$.

Finally, a comparative analysis of antibiotic resistance pattern of clinical isolates of $S$. aureus obtained in $1^{\text {st }}$ phase and $2^{\text {nd }}$ phase was done [Figure 2], which showed 30\% increase of resistance to ampicillin, chloramphenicol, and streptomycin. Maximum increase of resistance $(75 \%)$ was observed to erythromycin which is alarming and a great concern to the globe. Gentamicin resistance has also increased by $22 \%$.

\section{CONCLUSION}

Clinicians' prior choice is erythromycin or roxithromycin for any staphylococcal / any grampositive bacterial infections. But $92 \%$ of $S$. aureus have become erythromycin resistant today. $30 \%$ $S$. aureus are methicillin resistant; and if they contain mecA then there is a possibility to harbor erm gene classes and aadD genes in these strains, which might be a great risk factor for any severe gram-positive bacterial infection. So there is a great problem about the next choice of antimicrobial agent for treatment of staphylococcal and other gram-positive bacterial infections. Hence the time has come for thinking about the prudent use of antibiotics and carrying out antibiotic stewardship with more research all over the globe.

\section{ACKNOWLEDGEMENT}

We gratefully acknowledge the financial help from the Department of Science and Technology, Kolkata, Govt. of West Bengal, for this work.

\section{REFERENCES}

1. Morse SI (1980). Staphylococci. In: Davis BD, Dulbecco R, Eisen HN, and Ginsberg HS, (eds). Microbiology including immunology and molecular genetics. Third edition. Harper \& Row, Publishers. Philadelphia, pp. 623-633

2. Ayliffe GAJ (1997). The progressive intercontinental spread of methicillin-resistant Staphylococcus aureus. Clin Infect Dis;24 Suppl 1:S74-79

3. Simor AE (2001). Containing methicillinresistant S. aureus. Surveillance, control, and treatment methods. Postgrad Med 110:43-48

4. Pulimood TB, Lalitha MK, Jesudason MV, Pandian R, Selwyn J and Jacob T (1996). The spectrum of antimicrobial resistance among methicillin-resistant Staphylococcus aureus in a tertiary care center in India. Indian $\mathbf{J}$ Med Res 103:212-215

5. Saxena S, Singh K and Talwar V (2003). Methicillin-resistant Staphylococcus aureus prevalence in community in the east Delhi area. Japan J Infect Dis 56:54-56

6. Chambers HF (1997). Methicillin resistance in staphylococci: molecular and biochemical basis and clinical implications. Clin Microbiol Rev 10:781-791

7. Chabbert Y (1956). Antagonisme in vitro entre l'erythromycine et la spiramycine. Ann Inst Pasteur (Paris) 90:787-790

8. Bannerman TL (2003). Staphylococcus, Micrococcus, other catalase-positive cocci that grow aerobically. In: Murray PR, Baron EJ, Jorgensen JH, Pfaller MA and Yolken RH, (eds). Manual of clinical microbiology. ASM Press, Washington, DC, pp. 384-404

9. Turk DC and Porter IA (1978). Bacteria. In: Taylor S, (ed). A short text book of medical microbiology. 4th ed ELBS. Great Britain, pp. 83-160

10. Brakstad OG, Aasbakk K and Maeland JA (1992). Detection of Staphylococcus aureus by polymerase chain reaction amplification of the nuc gene. J Clin Microbiol 30:1654-1660

11. Woo PCY, Ng KHL, Lau SKP, Yip K-T, Fung AMY, Leung K-W, et al. (2003). Usefulness of the microSeq $500 \quad 16 \mathrm{~S}$ ribosomal DNA-based bacterial identification system for identification of clinically significant bacterial isolates with ambiguous biochemical profiles. J Clin Microbiol 41:1996-2001

12. Acar JF (1980). The disc susceptibility test. In: Lorian V, (ed). Antibiotics in laboratory medicine. Williams \& Wilkins, Baltimore, pp. 24-25

13. Bauer AW, Kirby WM, Sherris JC and Turck M (1966). Antibiotic susceptibility testing by a standardized single disk method. American J Clin Pathol 45:493-496

14. National Committee for Clinical Laboratory Standards (NCCLS). Methods for dilution antimicrobial susceptibility tests for bacteria that grow aerobically, Approved standard. $5^{\text {th }}$ ed. National Committee for Clinical Laboratory Standards, Wayne, Pa, USA. 2000; 17(2):M7-A5. This document is now renamed as Clinical and Laboratory Standards Institute / NCCLS. Performance Standards for Antimicrobial Susceptibility Testing. Sixteenth informational supplement. M100S16. Wayne, PA: CLSI, 2006. 
15. Dias CG, Rosa Ropke VR, Superti S, Berquo L and Azevedo P (2004). Use of a novel selective medium to detect methicillinresistant Staphylococcus aureus in colonized patients of an intensive care unit. Infect Contl Hosp Epid 25:130-132
16. Tiwari HK and Sen MR (2006). Emergence of vancomycin-resistant Staphylococcus Tiwari HK and Sen MR (2006). Emergence of vancomycin-resistant Staphylococcus aureus (VRSA) from a tertiary care hospital from northern part of India. BMC Infect Dis $6: 156$ 